\title{
Ventilation and gas exchange during sleep in patients with interstitial lung disease
}

\author{
WALTER T McNICHOLAS, MICHAEL COFFEY, MUIRIS X FITZGERALD
}

From the Department of Respiratory Medicine, St Vincent's Hospital, Dublin

\begin{abstract}
Ventilation and gas exchange during overnight sleep was studied in a group of seven patients with severe interstitial lung disease (mean vital capacity $50 \%$, mean diffusing capacity $46 \%$ predicted), to see whether clinically significant oxygen desaturation occurred. Patients with a history of loud snoring or clinically significant airflow obstruction were excluded. Sleep was fragmented in these patients, but all achieved rapid eye movement (REM) sleep. All patients showed episodes of oxygen desaturation during sleep-mean (SEM) awake arterial oxygen saturation $\left(\mathrm{SaO}_{2}\right)$ was $92.9 \%(0.3 \%)$ compared with a mean minimum $\mathrm{SaO}_{2}$ during sleep of $83.2 \%(2 \cdot 1 \%)(\mathrm{p}<0.01)$. These episodes were, however, transient, and mean $\mathrm{SaO}_{2}$ showed only a slight fall between wakefulness and sleep (non-REM 91.5\%, REM 90.4\%; NS). Furthermore, $\mathrm{SaO}_{2}$ during non-REM sleep correlated well $(\mathrm{p}<0.001)$ with $\mathrm{SaO}_{2}$ during wakefulness. Respiratory frequency showed a significant fall between wakefulness and sleep-21.1 (1.8) versus $17 \cdot 3(1.5)$ breaths per minute $(\mathrm{p}<0.02)$. Our data suggest that nocturnal oxygen treatment need not be considered in patients with interstitial lung disease unless the level of oxygenation while they are awake indicates the need for such treatment.
\end{abstract}

Patients with chronic obstructive lung disease may develop periods of profound oxygen desaturation during sleep, particularly during rapid eye movement (REM) sleep. ${ }^{1-4}$ This desaturation may be associated with serious cardiac arrhythmias, ${ }^{3}$ and may be an important determinant in the development of cor pulmonale in such patients. ${ }^{4}$ Furthermore, these nocturnal abnormalities may predispose to sudden death. ${ }^{5}$

Two recent studies have suggested that serious oxygen desaturation may occur in patients with interstitial lung disease. ${ }^{67}$ Both of these studies, however, included patients who snored, and one ${ }^{6}$ included patients with sleep apnoea. Since both of these factors can produce oxygen desaturation during sleep, such inclusions may have influenced the results. The question has important practical implications because of the documented benefits of supplemental nocturnal oxygen treatment in patients with chronic obstructive lung disease who show desaturation during sleep. ${ }^{389}$ If serious oxygen desaturation during sleep is a common feature in patients with interstitial lung disease,

Address for reprint requests: Dr W McNicholas, Department of Respiratory Medicine, St Vincent's Hospital, Dublin 4.

Accepted 10 March 1986 supplemental nocturnal oxygen treatment might need to be considered.

We have therefore measured ventilation and oxygenation during sleep in a group of patients with severe interstitial lung disease, specifically excluding patients with a history of loud snoring or with appreciable airflow obstruction.

\section{Methods}

We studied seven men with previously diagnosed interstitial lung disease. None had a history of loud snoring or daytime hypersomnolence and none had clinically significant airflow obstruction, although two patients had a slightly reduced $\mathrm{FEV}_{1} / \mathrm{FVC}$ ratio. Details are given in table 1 .

All patients underwent at least one overnight sleep study, and two patients underwent two separate studies. All sleep studies were performed with standard polysomnographic techniques, ${ }^{10}$ which included continuous recording of electroencephalogram (C4/Al and C3/A1 electrode positions), right and left electrooculogram, and submental electromyogram, all from surface electrodes. Ventilation was measured noninvasively using a respiratory inductance plethysmograph (Respitrace), which was calibrated by the least squares method. ${ }^{11}$ This device, when calibrated 
Table 1 Clinical, pulmonary function, ${ }^{*}$ and blood gas data

\begin{tabular}{|c|c|c|c|c|c|c|c|c|c|c|}
\hline $\begin{array}{l}\text { Patient } \\
\text { No }\end{array}$ & $\begin{array}{l}\text { Age } \\
(y)\end{array}$ & Diagnosis & $F E V_{1}$ & $F V C$ & $\begin{array}{l}F E V_{1} / \\
F V C \%\end{array}$ & $P E F$ & $T L C O$ & $\begin{array}{l}\mathrm{PaO}_{2} \\
(\mathrm{kPa})\end{array}$ & $\begin{array}{l}\mathrm{PaCO}_{2} \\
(\mathrm{kPa})\end{array}$ & $p H$ \\
\hline $\begin{array}{l}1 \\
2 \\
3 \\
4 \\
5 \\
6 \\
7 \\
\text { Mean } \\
\text { SEM }\end{array}$ & $\begin{array}{l}63 \\
46 \\
62 \\
62 \\
56 \\
62 \\
61 \\
59 \\
(3)\end{array}$ & $\begin{array}{l}\text { Fibrosing alveolitis } \\
\text { Farmer's lung } \\
\text { Fibrosing alveolitis } \\
\text { Fibrosing alveolitis } \\
\text { Farmer's lung } \\
\text { Fibrosing alveolitis } \\
\text { Fibrosing alveolitis }\end{array}$ & $\begin{array}{l}69 \\
44 \\
49 \\
70 \\
51 \\
62 \\
45 \\
56 \\
(5)\end{array}$ & $\begin{array}{l}60 \\
39 \\
48 \\
72 \\
44 \\
54 \\
36 \\
50 \\
(5)\end{array}$ & $\begin{array}{l}84 \\
88 \\
77 \\
72 \\
89 \\
84 \\
94 \\
84 \\
(3)\end{array}$ & $\begin{array}{l}87 \\
74 \\
75 \\
83 \\
71 \\
83 \\
87 \\
80 \\
(3)\end{array}$ & $\begin{array}{l}24 \\
59 \\
52 \\
32 \\
46 \\
82 \\
30 \\
46 \\
(8)\end{array}$ & $\begin{array}{r}9.4 \\
9.9 \\
8 \cdot 4 \\
8 \cdot 1 \\
10 \cdot 1 \\
11 \cdot 3 \\
5 \cdot 8 \\
9 \cdot 0 \\
(0 \cdot 7)\end{array}$ & $\begin{array}{l}5 \cdot 0 \\
6 \cdot 3 \\
4 \cdot 7 \\
5 \cdot 1 \\
6 \cdot 3 \\
4 \cdot 5 \\
5 \cdot 2 \\
5 \cdot 3 \\
(0 \cdot 3)\end{array}$ & $\begin{array}{l}7 \cdot 46 \\
7.41 \\
7 \cdot 45 \\
7 \cdot 43 \\
7 \cdot 41 \\
7 \cdot 45 \\
7 \cdot 50 \\
7.44\end{array}$ \\
\hline
\end{tabular}

*Data for FEV 1 , FVC, PEF, and TLCo are given as percentages of predicted normal values.

$\mathrm{FEV}_{1}$-forced expiratory volume in one second; FVC_-forced vital capacity; PEF-peak expiratory flow rate; TLco-diffusing capacity for carbon monoxide (single breath method); $\mathrm{PaO}_{2}$ - arterial partial pressure of oxygen; $\mathrm{PaCO}_{2}$-arterial partial pressure of carbon dioxide. Conversion-SI to traditional units: Blood gas data: $1 \mathrm{kPa}=7.5 \mathrm{~mm} \mathrm{Hg}$.

against a spirometer, provides a non-invasive measurement of tidal volume, ${ }^{11}$ and also allows differentiation of obstructive from central apnoea on the basis of, respectively, the presence or absence respectively, of out of phase movement in the ribcage and abdominal components of the Respitrace signal, where the sum channel indicates no net tidal volume. ${ }^{1112}$ In all subjects calibration was checked after the sleep study to determine whether correct calibration was maintained throughout the night. Four patients maintained satisfactory overnight calibration. Arterial oxygen saturation $\left(\mathrm{SaO}_{2}\right)$ was also recorded continuously using a Biox IIa ear oximeter. The electrocardiogram was obtained with a single praecordial lead. All signals were continuously recorded on a Grass Model 78D Polygraph recorder.

\section{ANALYSIS OF RESULTS}

Sleep stages were analysed in 30 second epochs according to the criteria of Rechtschaffen and Kales. ${ }^{10}$ The highest and lowest $\mathrm{SaO}_{2}$ values were measured for each minute of sleep and mean $\mathrm{SaO}_{2}$ for each minute was taken as the mean of the high and low $\mathrm{SaO}_{2}$ readings. From these data the mean $\mathrm{SaO}_{2}$ for each sleep stage was calculated. Respiratory fre- quency was calculated from the Respitrace recording for each patient during stable five minute periods of wakefulness and each of stages 1, 2, slow wave, anof REM sleep. In the four patients who maintained sat: isfactory calibration of the Respitrace through the night tidal volume was measured from the Respitraceo recording on a breath by breath basis during each of the above five minute periods, and minute ventilation was then calculated for each sleep stage. Statistica analysis was performed by paired $t$ testing, linear reㅡㅡㄴ gression analysis, or analysis of variance, as appropriő ate.

\section{Results}

Sleep stage distribution for each patient studied is given in table 2. Many of the patients had a fragmen ted sleep pattern with considerable periods of wake fulness during the night. All patients, however, hade lengthy periods of non-REM sleep and each patien? also went into REM sleep, although one (patient $7 \frac{5}{5}$. had only one brief period of REM. In fact, this pa $\frac{\rho}{2}$ tient, who had a very fragmented sleep pattern and was the most hypoxaemic of the group, was unable to fall asleep in the latter part of the night without sup $\frac{D}{0}$

Table 2 Sleep stage distribution

\begin{tabular}{|c|c|c|c|c|c|c|}
\hline \multirow{2}{*}{$\begin{array}{l}\text { Patient } \\
\text { No }\end{array}$} & \multicolumn{6}{|c|}{ Sleep stage* (minutes) } \\
\hline & Awake & $l$ & 2 & $S W S$ & $R E M$ & Totab \\
\hline $\begin{array}{l}1 \\
2 \\
3 \\
4 \\
5 \\
6 \\
7 \\
\text { Mean } \\
\text { SEM }\end{array}$ & $\begin{array}{r}73 \\
0 \\
1 \\
20 \\
82 \\
127 \\
162 \\
66 \\
26\end{array}$ & $\begin{array}{r}87 \\
53 \\
110 \\
120 \\
89 \\
18 \\
77 \\
79 \\
14\end{array}$ & $\begin{array}{l}106 \\
180 \\
167 \\
187 \\
148 \\
110 \\
118 \\
145 \\
14\end{array}$ & $\begin{array}{r}22 \\
71 \\
11 \\
1 \\
18 \\
22 \\
7 \\
22 \\
9\end{array}$ & $\begin{array}{r}22 \\
46 \\
61 \\
46 \\
52 \\
34 \\
2 \\
38 \\
8\end{array}$ & 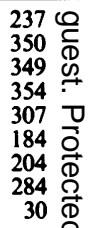 \\
\hline
\end{tabular}

*Awake represents time spent awake between the onset of sleep and the final awakening in the morning. ${ }^{11}$ SWS - slow wave

sleep;REM-rapid eye movement sleep; stages 1 and 2, and slow wave sleep comprise non-REM sleep. Total values exclude periods of wakefulness. 
plemental oxygen, the oxygen being switched off when stable sleep was achieved. His one brief period of REM sleep occurred while he was having supplemental oxygen. A second patient (No 4) also had difficulty falling asleep without supplemental oxygen and no stable period of wakefulness could be achieved while he was breathing room air. He did, however, have long periods of both non-REM and REM sleep while breathing room air. None of the other patients had recourse to supplemental oxygen while we were studying them.

Details of oxygenation are given in table 3. Periods of sleep during administration of supplemental oxygen and for 15 minutes thereafter in patients 4 and 7 were ignored, and thus $\mathrm{SaO}_{2}$ data during REM sleep in patient 7 are not included since he was having supplemental oxygen at this time. All patients developed episodes of oxygen desaturation during sleep ( $p<0.01$ ), but these episodes were transient. The mean $\mathrm{SaO}_{2}$ showed only a slight fall during both nonREM and REM sleep, which was not significant by analysis of variance. The lowest mean $\mathrm{SaO}_{2}$ during sleep was seen in the patient with the most severe hyp- oxaemia while awake (patient 7). This patient died within one month of study. There was a strong correlation in individual patients between mean awake $\mathrm{SaO}_{2}$ and mean $\mathrm{SaO}_{2}$ during non-REM sleep ( $\mathrm{r}=$ $0.98 ; \mathrm{p}<0.001$ ), but the correlation was not as close with mean $\mathrm{SaO}_{2}$ during REM sleep, which may in part be accounted for by the lack of data on $\mathrm{SaO}_{2}$ during REM sleep for the most hypoxaemic patient (patient 7).

Two patients had periods of apnoea during sleep. One (patient 1) had a Cheyne-Stokes breathing pattern, which was associated with recurring central apnoea during both wakefulness (48 episodes of apnoea an hour) and non-REM sleep (52 episodes an hour). This breathing pattern was abolished during REM sleep and in this patient, unlike the others, mean $\mathrm{SaO}_{2}$ was no lower during REM sleep than during either non-REM sleep or wakefulness (table 3). A second (patient 5) had 37 episodes of obstructive apnoea during sleep (7.2 episodes per hour of sleep). Neither patient had more than $2-3 \%$ oxygen desaturation during these apnoeic episodes.

Respiratory frequency showed a significant fall be-

Table 3 Changes* in arterial oxygen saturation ( $\mathrm{SaO}_{2}$ ) between wakefulness and sleep in seven patients with interstitial lung disease

\begin{tabular}{|c|c|c|c|c|c|c|}
\hline \multirow{3}{*}{$\begin{array}{l}\text { Patient } \\
\text { No }\end{array}$} & \multirow{3}{*}{$\begin{array}{l}\text { Mean } \\
\text { awake }\end{array}$} & \multicolumn{5}{|c|}{ Arterial oxygen saturation } \\
\hline & & \multicolumn{4}{|c|}{ Sleep stage } & \multirow{2}{*}{$\begin{array}{l}\text { Minumum } \\
\text { during } \\
\text { sleep }\end{array}$} \\
\hline & & $l$ & 2 & $S W S$ & $R E M$ & \\
\hline 1 & 94 & 94 & 93 & 94 & 94 & 89 \\
\hline 2 & 93 & 91 & 91 & 91 & 90 & 77 \\
\hline 3 & 94 & 93 & 93 & 92 & 91 & 84 \\
\hline 4 & 92 & 92 & 91 & 88 & 87 & 77 \\
\hline 5 & 92 & 92 & $9 i$ & 92 & 91 & 87 \\
\hline 6 & 92 & 92 & 90 & 89 & 90 & 85 \\
\hline 7 & 81 & 81 & 82 & 81 & $-\dagger$ & 80 \\
\hline Meant & $92 \cdot 9$ & $92 \cdot 1$ & $91 \cdot 5$ & $91 \cdot 0$ & $90 \cdot 4$ & $83 \cdot 2$ \\
\hline SEM & $0 \cdot 3$ & 0.4 & 0.4 & 1.0 & $1 \cdot 0$ & $2 \cdot 1$ \\
\hline
\end{tabular}

*Differences between awake $\mathrm{SaO}_{2}$ and minimum $\mathrm{SaO}_{2}$ are significant at the $1 \%$ level (paired $t$ test). Differences between awake $\mathrm{SaO}_{2}$ and mean values during each sleep stage are not significant (analysis of variance).

tREM value not given for this patient as he was having supplemental oxygen during this period (see text for details).

† Mean value given for patients $1-6$ only.

SWS-slow wave sleep; REM — rapid eye movement sleep.

Table 4 Indices of ventilation during wakefulness and sleep in seven patients with interstitial lung disease

\begin{tabular}{|c|c|c|c|c|c|c|c|c|c|c|c|c|}
\hline \multirow{2}{*}{$\begin{array}{l}\text { Patient } \\
\text { No }\end{array}$} & \multicolumn{3}{|c|}{ Awake } & \multicolumn{3}{|c|}{ Mean sleep } & \multicolumn{3}{|c|}{ Non-REM sleep } & \multicolumn{3}{|c|}{ REM sleep } \\
\hline & $\dot{V}_{E}$ & $V T$ & $f^{*}$ & $\dot{V}_{E}$ & $V T$ & $f^{*}$ & $V_{E}$ & $V T$ & $f^{*}$ & $\dot{V}_{E}$ & $V T$ & $f^{*}$ \\
\hline $\begin{array}{l}1 \\
2 \\
3 \\
4 \\
5 \\
6 \\
7 \\
\text { Mean } \\
\text { SEM }\end{array}$ & $\begin{array}{c}10 \cdot 1 \\
5 \cdot 2 \\
8 \cdot 1 \\
- \\
= \\
= \\
-\end{array}$ & $\begin{array}{l}720 \\
226 \\
386 \\
- \\
- \\
- \\
-\end{array}$ & $\begin{array}{l}14 \\
23 \\
21 \\
18 \\
20 \\
25 \\
27 \\
21 \cdot 1 \\
1.8\end{array}$ & $\begin{array}{l}9 \cdot 5 \\
5 \cdot 9 \\
8 \cdot 1 \\
11 \cdot 4 \\
- \\
- \\
-\end{array}$ & $\begin{array}{l}730 \\
350 \\
515 \\
600 \\
- \\
- \\
- \\
-\end{array}$ & $\begin{array}{l}13 \\
17 \\
15 \cdot 5 \\
18 \cdot 5 \\
13 \cdot 5 \\
20 \\
23.5 \\
17 \cdot 3 \\
1.5\end{array}$ & $\begin{array}{r}9 \cdot 9 \\
6 \cdot 2 \\
8 \cdot 3 \\
12 \cdot 2 \\
- \\
- \\
-\end{array}$ & $\begin{array}{l}812 \\
370 \\
509 \\
650 \\
- \\
- \\
-\end{array}$ & $\begin{array}{l}12 \\
17 \\
16 \\
18 \\
15 \\
21 \\
24 \\
17 \cdot 6 \\
1.5\end{array}$ & $\begin{array}{l}9.1 \\
5.6 \\
7.8 \\
10 \cdot 5 \\
- \\
- \\
-\end{array}$ & $\begin{array}{l}650 \\
329 \\
520 \\
553 \\
- \\
- \\
-\end{array}$ & $\begin{array}{l}14 \\
17 \\
15 \\
19 \\
12 \\
19 \\
23 \\
17 \cdot 0 \\
1.6\end{array}$ \\
\hline
\end{tabular}

*Differences in $\mathrm{f}$ between wakefulness and mean sleep are significant at the $2 \%$ level (paired $t$ test).

$\dot{\mathrm{V}} \mathrm{E}-$ minute ventilation $\left(\mathrm{l} / \mathrm{min}^{-1}\right) ; \mathrm{VT}$ - tidal volume $(\mathrm{ml}) ; \mathrm{f}-$ respiratory frequency (breaths $\left./ \mathrm{min}\right)$. 
tween wakefulness and sleep (table 4). Frequency was similar during REM and non-REM sleep. In the four patients in whom satisfactory calibration of the Respitrace was maintained throughout the night minute ventilation showed a consistent fall from non-REM to REM sleep (table 4). There was, however, no significant difference in minute ventilation between wakefulness and sleep. Tidal volume tended to be higher during sleep than during wakefulness.

None of the patients had any appreciable cardiac irregularities during sleep.

\section{Discussion}

These data indicate that, while oxygen desaturation does occur during sleep in patients with interstitial lung disease, this desaturation is minor and unlikely to be of clinical importance. Thus our findings indicate that oxygenation during sleep in patients with interstitial lung disease is similar to that of "pink puffer" patients with chronic obstructive lung disease, ${ }^{124}$ who also develop only mild oxygen desaturation during sleep, unlike "blue bloater" patients, who may develop profound oxygen desaturation associated with serious ventricular arrhythmias. $^{3}$ In fact, the levels of oxygen desaturation during sleep in our patient population are no greater than those shown by normal subjects during sleep in one previous report. ${ }^{13}$ In patients with chronic obstructive lung disease, however, the degree of nocturnal hypoxaemia has been shown to correlate with the level of daytime hypoxaemia. ${ }^{214}$ Since only one of our patients was severely hypoxaemic during wakefulness, and this patient had little REM sleep, our data do not exclude the possibility that severely hypoxaemic patients with interstitial lung disease might show appreciable desaturation during sleep. This could result from the combined effects of the slight decrease in ventilation that is a normal feature of sleep ${ }^{15}$ and the fact that such severely hypoxaemic patients would be on the steep portion of the oxyhaemoglobin dissociation curve, which would mean that small changes in arterial oxygen tension would produce relatively large changes in $\mathrm{SaO}_{2}$.

Our findings contrast with those of Bye et $a l^{6}$ and Perez-Padilla et al, ${ }^{7}$ which represent the only other reports on oxygenation during sleep in such patients. Bye et al reported clinically significant oxygen desaturation during sleep in most of their patients with interstitial lung disease. They reported, however, only minimum $\mathrm{SaO}_{2}$ during sleep, and no data on mean $\mathrm{SaO}_{2}$ were given. Furthermore, the lowest $\mathrm{SaO}_{2}$ levels were seen in those patients who snored or had associated airflow obstruction, and two of their patients were found to have repetitive episodes of obstructive apnoea during sleep. Since oxygen desaturation during sleep occurs with obstructive sleep apnoea, this finding may have confounded theit results. Heavy snorers were specifically excluded fror our study, although one patient was unexpectedf found to have a small number of episodes of obstrue tive apnoea during sleep. These episodes, however were associated with only a minor degree of oxygef desaturation. Perez-Padilla et al also reported significant desaturation, particularly during REA sleep, in their patients with interstitial lung disease but again most of their patients snored. It is, howevek, apparent from their data that mean $\mathrm{SaO}_{2}$ showed on a small fall during the various sleep stages, similar to our findings. The difference in degree of oxygen desaturation during sleep between our patients and those reported by Bye et al and Perez-Padilla et 9 cannot be explained by differences in oxygenation during wakefulness since our patients had a lowe mean arterial $\mathrm{Po}_{2}$ during wakefulness than those $\mathscr{f}$ Bye et al, and had values similar to those of th patients of Perez-Padilla et al.

Hypoxaemic patients with interstitial lung disea多 would not necessarily be expected to show changes in oxygenation during sleep similar to those found patients with chronic obstructive lung disease wi equivalent levels of hypoxaemia. The hypoxaem seen during sleep, particularly REM sleep, in patien with chronic obstructive lung disease has a mult factorial basis, ${ }^{214-16}$ related to changes in respir tory drive, changes in functional residual capacity $\mathscr{G}$ the lung, inhibition of accessory muscles of respira tion, and impaired function of the diaphragm related to hyperinflation. Some of these factors-for exans ple, impaired diaphragm function-would not app in patients with interstitial lung disease.

Patients with interstitial lung disease typically has a rapid shallow breathing pattern during wakefulness; which is likely to be a vagally mediated response decreased lung compliance. ${ }^{17-19}$ These patients also have increased ventilatory drive, which is associatef with increased minute ventilation and hypo capnia. ${ }^{17-19}$ In this regard they are similar to pine puffer patients with chronic obstructive lung disease who also have evidence of increased ventilatory drive. ${ }^{20}$ The ventilatory changes seen in patients wi interstitial lung disease while awake are probably doe to the effects of stimulation of lung parenchyman receptors, since vagal blockade has been shown decrease minute ventilation in patients with intexstitial lung disease. ${ }^{21}$ There is little published infortmation on the effects of sleep on vagally mediated reflexes in man, although studies in animals on to effects of vagal blockade and of lung inflation ${ }^{22} \$_{3}$ suggest that vagally mediated reflexes are intact ar possibly even increased during non-REM sleep. The effect of REM sleep on these reflexes is less clearcut in 
that the influence of vagal stimuli on breathing is more variable, but overall there does appear to be some reduction in the response to vagal stimuli during REM sleep. ${ }^{22} 23$

Our patients showed a higher respiratory frequency during wakefulness than during either non-REM or REM sleep. This finding contrasts with several recent studies of ventilation during sleep in normal adult subjects, ${ }^{24-26}$ which found no significant differences in respiratory frequency between wakefulness and sleep, although the finding is in partial agreement with those of previous animal studies, which have shown a greater respiratory frequency during wakefulness than during non-REM sleep but a rise in frequency during REM sleep. ${ }^{22}{ }^{23}$ This finding differs also from that of Perez-Padilla $e t$ al, ${ }^{7}$ who found no significant difference in respiratory frequency between wakefulness and sleep, although there did appear to be a trend towards a fall. In most of our patients the period of wakefulness chosen for analysis was in the early part of the night. Thus patients may have been anxious during this period of wakefulness, which might in part have accounted for their rapid breathing. On the other hand, the breathing frequencies seen in our patients during wakefulness were similar to those found in other studies in awake patients with interstitial lung disease. ${ }^{1827}$

In three of the four patients in whom calibration of the Respitrace was maintained throughout the night differences in $\mathrm{SaO}_{2}$ between non-REM and REM sleep were accompanied by similar differences in minute ventilation. The one patient in whom $\mathrm{SaO}_{2}$ rose during REM sleep despite a fall in minute ventilation was the patient with Cheyne-Stokes breathing during non-REM sleep, which was abolished during REM sleep. These findings suggest that the fall in $\mathrm{SaO}_{2}$ seen in REM sleep in these patients was at least partly due to hypoventilation. The findings do not, of course, exclude the possibility that other factors contribute to the fall in $\mathrm{SaO}_{2}$, such as changes in ventilation-perfusion relationships.

Sleep was more disturbed in our patients than in normal subjects of similar age. ${ }^{28}$ These findings agree with those of Perez-Padilla et al, ${ }^{7}$ and with other studies of patients with chronic obstructive lung disease. ${ }^{8}$ The sleep fragmentation may have been due in part to a "first night effect" related to the strange surroundings and the monitoring equipment. ${ }^{29}$ In the absence of age matched control subjects therefore we cannot say how much of the sleep fragmentation seen in our patients was related to the effects of their pulmonary disease. Sleep quality did not, however, improve appreciably on the second night in those patients who had two sleep studies.

Our findings have several important clinical implications. Firstly, the relatively minor degree of oxygen desaturation during sleep in our patients with interstitial lung disease indicates that supplemental nocturnal oxygen need not be routinely considered in such patients unless the degree of hypoxaemia while they are awake calls for such treatment. Secondly, our data indicate that the level of oxygenation during sleep in patients with interstitial lung disease can be roughly predicted from blood gas data obtained during wakefulness. Thus overnight monitoring of gas exchange in such patients need not be considered unless there is a clinical suspicion of a specific sleep related respiratory disorder such as sleep apnoea.

\section{References}

1 Douglas NJ, Calverley PMA, Leggett RJE, Brash HM, Flenley DC, Brezinova V. Transient hypoxaemia during sleep in chronic bronchitis and emphysema. Lancet 1979;i:1-4.

2 Littner MR. McGinty DJ, Arand DL. Determinants of oxygen desaturation in the course of ventilation during sleep in chronic obstructive pulmonary disease. Am Rev Respir Dis 1980;122:849-57.

3 Tirlapur VG, Mir MA. Nocturnal hypoxemia and associated electrocardiographic changes in patients with chronic obstructive airways disease. $N$ Engl J Med 1982;306:125-30.

4 DeMarco FJ, Wynne JW, Block AJ, Boysen PG, Taasan VC. Oxygen desaturation as a determinant of the blue and bloated syndrome. Chest 1981;79:621-5.

5 McNicholas WT, FitzGerald MX. Nocturnal deaths among patients with chronic bronchitis and emphysema. Br Med J 1984;289:878.

6 Bye PTP, Issa F, Berthon-Jones M, Sullivan CE. Studies of oxygenation during sleep in patients with interstitial lung disease. Am Rev Respir Dis 1984;129:27-32.

7 Perez-Padilla R, West P, Lertzman M, Kryger $\mathbf{M H}$. Breathing during sleep in patients with interstitial lung disease. Am Rev Respir Dis 1985;132:224-9.

8 Goldstein RS, Ramcharan V, Bowes G, McNicholas WT, Bradley D, Phillipson EA. Effect of supplemental nocturnal oxygen on gas exchange in patients with severe obstructive lung disease. N Engl J Med 1984; 310:425-9.

9 Medical Research Council Working Party. Long-term domiciliary oxygen therapy in chronic hypoxic cor pulmonale complicating chronic bronchitis and emphysema. Lancet 1981;i:681-6.

10 Rechtshaffen A, Kales A. A manual of standardised terminology, techniques and scoring system for sleep stages in human subjects. Washington DC: National Institutes of Health, 1968. (Publication 204).

11 Chadha TS, Watson H, Birch S, et al. Validation of respiratory inductance plethysmography using different calibration procedures. Am Rev Respir Dis 1982;125:644-9.

12. Hyland RH, Hutcheon MA, Perl A, et al. Upper airway occlusion induced by diaphragm pacing for primary alveolar hypoventilation: implications for the pathogenesis of obstructive sleep apnea. Am Rev Respir Dis 1981;124:180-5. 
13 Block AJ, Boysen PG, Wynne JW, Hunt LA. Sleep apnea, hypopnea and oxygen desaturation in normal subjects. New Engl J Med 1979;300:513-7.

14 Stradling JR, Lane DJ. Nocturnal hypoxaemia in chronic obstructive pulmonary disease. Clin Sci 1983; 64:213-22.

15 Phillipson EA. Control of breathing during sleep. Am Rev Respir Dis 1978;118:909-39.

16 Hudgel DW, Martin RJ, Capehart M, Johnson B, Hill P. Contribution of hypoventilation to sleep oxygen desaturation in chronic obstructive pulmonary disease. J Appl Physiol: Respirat Environ Exercise Physiol 1983;55:669-77.

17 Lourenco RV, Turino GM, Davidson LAG, Fishman AP. The regulation of ventilation in diffuse pulmonary fibrosis. Am J Med 1965;38:199-216.

18 Savoy J, Dhingra S, Anthonisen NR. Role of vagal airway reflexes in the control of ventilation in pulmonary fibrosis. Clin Sci Mol Med 1981;61:781-4.

19 Meerhaege AV, Scano G, Sergyels R, Bran M, DeCoster A. Respiratory drive and ventilatory pattern during exercise in interstitial lung disease. Bull Eur Physiopathol Respir 1981;71:15-26.

20 Lourenco RV, Miranda JM. Drive and performance of the ventilatory apparatus in chronic obstructive lung disease. N Engl J Med 1968;279:53-9.

21 Guz A, Noble MIM, Eisele JH, et al. Experimental results of vagal block in cardiopulmonary disease. In:
Porter R, ed. Breathing: Hering-Breuer Centenary Symposium. London: Churchill, 1970:315-29.

22 Phillipson EA, Murphy E, Kozar LF. Regulation of respiration in sleeping dogs. J Appl Physiol: Respira馬 Environ Exercise Physiol 1976;40:688-93.

23 Sullivan CE, Murphy E, Kozar LF, Phillipson EA Ventilatory responses to $\mathrm{CO}_{2}$ and lung inflation in tonic versus phasic REM sleep. J Appl Physiol: Respirat Environ Exercise Physiol 1979;47:1304-10.

24 Gothe B, Altose M, Goldman MD, Cherniask NS. Effect of quiet sleep on resting and $\mathrm{CO}_{2}$-stimulated breathing in humans. J Appl Physiol: Respirat Environ Exercise्ट्र Physiol 1981;50:724-30.

25 Hudgel DW, Martin RJ, Johnson B, Hill P. Mechanics of the respiratory system and breathing pattern during $\overrightarrow{0}$ sleep in normal humans. J Appl Physiol: Respirat Envi-y ron Exercise Physiol 1984;56:133-7.

26 Stradling JR, Chadwick GA, Frew AJ. Changes in ventio lation and its components in normal subjects during sleep. Thorax 1985;40:364-70.

27 Tobin MJ, Chadha TS, Jenouri G, Birch SJ, Gazenoglug HB, Sackner MA. Breathing patterns-2: Disease of subjects. Chest 1983;84:286-94.

28 Williams RL, Karacan I, Hursch CJ. EEG of humansleep: clinical applications. New York: Wiley, 1974.

29 Agnew HW, Webb WB, Williams RL. The first nighe effect: an EEG study of sleep. Psychophysiology 1966 2:263-6. 